\title{
A QUÍMICA DOS ÉSTERES DE FOSFATO
}

Josiel B. Domingos, Elisane Longhinotti, Vanderlei Gageiro Machado e Faruk Nome*

Departamento de Química, Universidade Federal de Santa Catarina, CP 476, 88040-900 Florianópolis - SC

Recebido em 5/11/02; aceito em 29/1/03

THE CHEMISTRY OF PHOSPHATE ESTERS. This work summarizes important aspects of the chemistry of phosphate esters, with special emphasis on: i) advances in the design of enzymatic models for phosphatases; and ii) nerve agents and currently used strategies for detoxification. The physical organic chemical aspects that are responsible by the reactivity of phosphate esters are also discussed.

Keywords: phosphate esters; nerve agents; enzymatic models.

\section{INTRODUÇÃO}

O fósforo é um elemento vital na composição da matéria viva e não se conhece um organismo vivo que não utilize a química deste elemento. Os animais absorvem o fósforo a partir do alimento ingerido e grande parte do $\mathrm{P}$ encontra-se nos mesmos como "fosfato orgânico", nas formas de mono e diésteres (ligações C-O-P). Além de fosfatos orgânicos há polifosfatos inorgânicos e uma variedade de compostos importantes com ligações N-P (fosfocreatinina, fosfoarginina), bem como em microorganismos têm sido caracterizados compostos contendo ligações $\mathrm{P}-\mathrm{C}^{1}$.

O corpo humano contém aproximadamente $1 \%$ em massa deste elemento e, embora esta quantidade de fósforo orgânico seja pequena, seu papel é essencial nos processos celulares. Os ésteres fosfóricos são os principais responsáveis pelo armazenamento e transmissão de informação genética (os fosfodiésteres DNA e RNA)², participam na estrutura de várias coenzimas ${ }^{3}$ e, anidridos fosfóricos e compostos orgânicos contendo ligações N-P servem como principal reserva de energia [trifosfato de adenosina (ATP), creatina fosfato, acetilfosfato $(\mathrm{AcP})$, fosfoenolpiruvato e polifosfato inorgânico $]^{4,5}$. Além da sua importância em processos biológicos, os ésteres fosfóricos encontram aplicações como plastificantes, reagentes na preparação de polímeros organofosforados, complexantes para a extração de cátions de metais pesados, inseticidas, pesticidas e compostos tóxicos utilizados em armas de guerra ${ }^{6}$.

Os ésteres fosfóricos são extremamente numerosos e podem ser classificados em mono-, di- e triésteres, de acordo com o número de grupos ésteres presentes, sendo que os triésteres não participam em processos biológicos. Os mono- e diésteres do ácido fosfórico contêm grupos hidroxila na sua estrutura caracterizando-se, portanto, como ésteres com uma funcionalidade adicional equivalente à de ácidos dipróticos ou monopróticos, respectivamente.<smiles>[R6]P(=O)(O)O</smiles>

monoéster<smiles>[R]OP([R])(=O)O</smiles>

diéster<smiles>[R]OP([R])(=O)O</smiles>

triéster
A solução encontrada pela natureza para garantir aos seres vivos a sua perpetuação deu-se pelo uso das ligações $\mathrm{P}-\mathrm{O}$ para formar os fosfodiésteres DNA e RNA. A evolução encontrou esta ligação como a ideal para este propósito devido à estabilidade dos diésteres de fosfato. É interessante observar que compostos organofosforados foram selecionados pelo homem para desenvolver pesticidas, inseticidas e gases de guerra. As ligações P-O são ideais para o desenho destas classes de compostos, já que os tornam resistentes à ação da água, do solo e do ar, a fim de que possam atingir o seu alvo sem serem alterados quimicamente, ficando aptos para acumular nos tecidos e provocar danos aos seres vivos. O presente trabalho concentra-se sobre este aspecto dualístico dos ésteres de fosfato enquanto agentes responsáveis pela vida e, circunstancialmente, por danos em nosso planeta. Assim, apresenta-se uma revisão ampla da química dos ésteres de fosfato, em especial sobre os aspectos referentes a agentes neurotóxicos e sobre os estudos de modelos para as enzimas responsáveis pela formação e quebra das ligações envolvendo átomos de fósforo e oxigênio. Inicialmente, será feita uma abordagem físico-química orgânica dos processos de substituição nucleofílica em ésteres de fosfato.

\section{REAÇÕES DE SUBSTITUIÇÃO NUCLEOFÍLICA EM ÉSTERES FOSFÓRICOS}

As ligações encontradas nos fosfodiésteres podem ser muito estáveis. O tempo de meia vida $\left(t_{1 / 2}\right)$ para a hidrólise de certos ésteres fosfóricos de longe excede o tempo de vida alcançado por um ser humano. Assim, por exemplo, o $t_{1 / 2}$ para a reação de hidrólise espontânea do difenilfosfato é de 180 anos a $100{ }^{\circ} \mathrm{C}^{7}$. A hidrólise espontânea do DNA em solução neutra é tão lenta que a constante de velocidade para este processo é desconhecida ${ }^{8}$. Tal estabilidade é coerente com o papel fundamental do DNA na preservação da informação genética.

Em essência, dois mecanismos fundamentais para uma reação de substituição nucleofílica de ésteres fosfóricos são conhecidos. No primeiro, o átomo de carbono da ligação P-O-C do éster pode servir como eletrófilo, sendo todo o grupo fosfato substituído pelo nucleófilo. No segundo, o nucleófilo ataca o átomo de fósforo central e desloca o álcool ou o alcóxido via quebra da ligação P-O, mantendo a ligação C-O intacta (Esquema 1).

O mecanismo de quebra da ligação alquil-oxigênio somente é o caminho principal em $\mathrm{pH}$ baixo, onde o grupo de saída é o ácido fosfórico neutro. A hidrólise de ésteres fosfóricos, tais como o benzil 


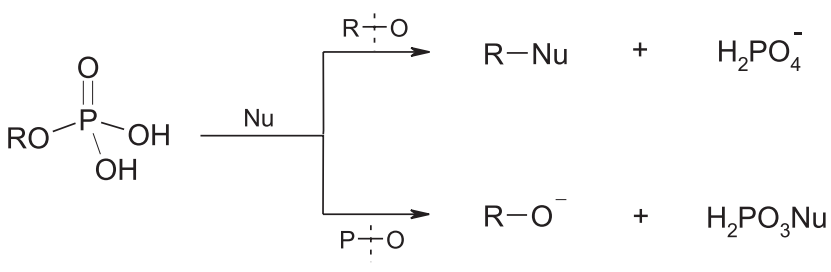

Esquema 1

e o terc-butilfosfato, que possuem grupos alquílicos que formam carbocátions estáveis pela quebra da ligação C-O (alquilfosfatos terciários), ocorre via um processo de ionização $\mathrm{S}_{\mathrm{N}} 1$.

Em pH baixo, os alquilfosfatos primários e secundários são hidrolisados através de dois mecanismos competitivos, por $\mathrm{S}_{\mathrm{N}} 2$ com clivagem da ligação alquil-oxigênio ou por quebra da ligação $\mathrm{P}-\mathrm{O}^{9}$. Acima de $\mathrm{pH} 1,5$, onde o grupo de saída fosfato possui pelo menos uma carga negativa, a hidrólise processa-se principalmente via mecanismos de clivagem da ligação $\mathrm{P}-\mathrm{O}^{10}$. As reações enzimáticas ocorrem, na sua grande maioria, por clivagem da ligação P-O do éster fosfórico ${ }^{11}$. Entretanto, há um grupo importante de enzimas, envolvidas na transferência de unidades de glicose e fucose, onde a reação procede por um mecanismo que envolve a quebra da ligação $\mathrm{C}-\mathrm{O}^{12}$.

As reações de substituição em ésteres fosfóricos com quebra da ligação P-O têm sido, por muito tempo, consideradas mecanisticamente análogas àquelas envolvendo substituição no carbono tetraédrico, do tipo $\mathrm{S}_{\mathrm{N}} 1$ ou $\mathrm{S}_{\mathrm{N}}{ }^{10}$. Estes mecanismos têm sido descritos na literatura ${ }^{10,13}$ como pertencentes a duas classes: dissociativo e associativo.

O mecanismo dissociativo procede através da liberação do íon metafosfato hidratado $\left(\mathrm{PO}_{3}^{-}\right)$, sendo análogo ao processo $\mathrm{S}_{\mathrm{N}} 1$ na química do carbono. $\mathrm{O}$ ânion metafosfato gerado é uma espécie trigonal e pode reagir com um nucleófilo por ambas as faces (Esquema 2).

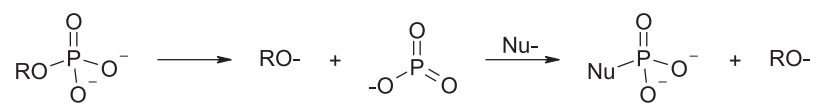

Esquema 2

Os mecanismos associativos de adição-eliminação, denominados $\mathrm{S}_{\mathrm{N}} 2(\mathrm{P})$, são análogos ao mecanismo $\mathrm{S}_{\mathrm{N}} 2$ para a substituição no átomo de carbono. A espécie formada no ataque do nucleófilo sobre o átomo de fósforo tetraédrico é pentacoordenada com geometria do tipo bipirâmide trigonal (BP.T.), sendo esta espécie um intermediário ou um estado de transição. Os mecanismos associativos podem ser representados de acordo com o Esquema 3.

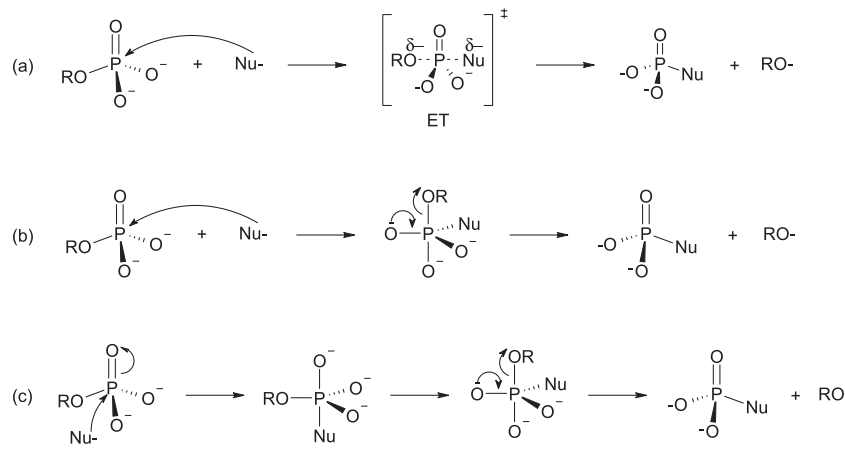

Esquema 3

O mecanismo representado em (a) mostra um processo associativo em linha, onde o estado de transição (E.T.) é pentacoordenado, com o nucleófilo e o grupo de saída nas posições apicais parcialmente ligados ao átomo de fósforo central, levando à inversão de configuração. $\mathrm{O}$ mecanismo (b) também apresenta um processo associativo em linha, mas leva a um intermediário pentacoordenado estável e à inversão de configuração. Finalmente, o mecanismo apresentado em (c) mostra retenção de configuração em um processo associativo adjacente, pelo qual o intermediário pentacoordenado sofre uma pseudo-rotação para que o grupo de saída fique na posição apical.

É importante lembrar que a posição apical de um fósforo numa geometria BP.T. é favorável sobre a posição equatorial, tanto para o ataque do nucleófilo quanto para a partida do grupo de saída. São duas as razões para justificar esta preferência: primeiramente, a ligação apical é o resultado da interação do nucleófilo com uma determinada face do átomo de fósforo tetraédrico no estado fundamental para providenciar um impedimento estéreo reduzido dos grupos vizinhos. Além disso, as ligações apicais possuem comprimentos maiores e são mais fracas que as equatoriais ${ }^{14}$.

Os mecanismos de substituição nucleofílica de ésteres fosfóricos são complexos devido ao possível envolvimento de diversas espécies. O substrato corresponde, normalmente, a uma mistura de ésteres fosfóricos neutros, monoaniônicos e/ou dianiônicos, dependendo do $\mathrm{pH}$. Um método bastante útil para visualizar estes mecanismos, dissociativo e associativo, e suas variantes, corresponde ao diagramas simplificado de coordenada de reação mostrado na Figura 1. Neste diagrama, o progresso do ataque do nucleófilo providencia uma coordenada (ligação P-X), sendo que a partida do grupo de saída providencia a segunda coordenada (ligação P-Y).

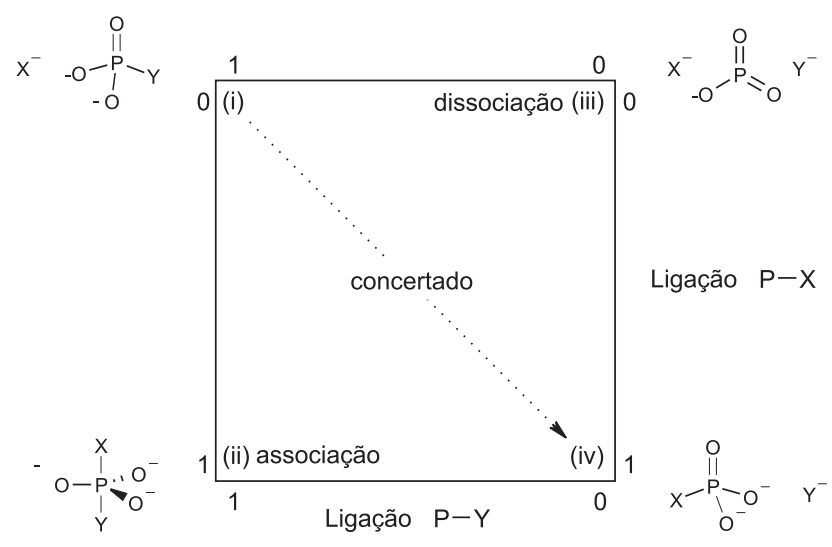

Figura 1. Diagrama simplificado de coordenada de reação para a transferência do grupo fosforila entre os grupos axiais $X$ e $Y$

No diagrama, os mecanismos com mais de uma etapa envolvem os caminhos ao longo das bordas do diagrama, enquanto os mecanismos concertados envolvem caminhos que desviam das bordas. Em uma das arestas do diagrama está o átomo de fósforo pentacoordenado (ii), cuja existência tem sido demonstrada experimentalmente ${ }^{15}$. As reações concertadas esquivam-se desta aresta, mas muitos mecanismos de reações de substituição apresentando mais de uma etapa envolvem estas espécies como intermediários. A aresta diagonalmente oposta ao átomo de fósforo pentacoordenado é ocupada por uma espécie trigonal do fósforo (iii), que é ou o metafosfato monomérico (no caso da reação de um monoéster) ou um derivado substituído. Contudo, não tem sido demonstrado experimentalmente o envolvimento de tal espécie em um processo de substituição apresentando mais de uma etapa em solução aquosa.

Apesar de haver evidências que favorecem cada um dos mecanismos descritos acima ${ }^{10,15-17}$, ainda não há consenso em relação aos 
verdadeiros mecanismos. O ponto de vista dominante atual com relação às reações de hidrólise e de transferência do grupo fosforila dos ésteres fosfóricos em solução considera que os diésteres e triésteres seguem um caminho associativo, enquanto os monoésteres seguem um mecanismo com característica dissociativa. Esta última reação procede sem que o metafosfato livre seja formado, necessariamente, como intermediário, mas o E.T. da etapa determinante envolve principalmente a quebra da ligação do grupo de saída com pequena formação da ligação com o nucleófilo ${ }^{18}$. Em termos do diagrama na Figura 1, este mecanismo envolve caminhos de reação que se aproximam da aresta ocupada pelo intermediário metafosfato, mas não o alcança.

Usando cálculos ab initio, Florián e Warshel ${ }^{13}$ estudaram a hidrólise não enzimática do monofosfato de metila (neutro, monoânion e diânion) verificando as energias associadas ao ataque nucleofílico, pela água ou pelo íon hidróxido, ao átomo de fósforo central. Os resultados indicam que a hidrólise do fosfato de metila neutro procede via mecanismo associativo. Em relação à reação de hidrólise do fosfato de metila mono- e dianiônico, os cálculos teóricos mostram que as barreiras de ativação dos caminhos associativo e dissociativo são similares, indicando que o sítio ativo de uma enzima poderia selecionar entre estes mecanismos, dependendo particularmente do ambiente eletrostático ${ }^{13}$.

O estudo físico-químico orgânico de reações modelo pode contribuir significativamente para a compreensão do mecanismo de ação de muitas enzimas. Compostos organofosforados, tais como o ATP e o AcP, desempenham um papel biológico muito importante em processos de transferência de energia. Assim, os mecanismos da reação de hidrólise de AcP e outros anidridos relacionados têm sido amplamente investigados ${ }^{5}$. A idéia recente de que estes compostos são formados espontaneamente no sítio ativo das enzimas responsáveis por sua síntese, em uma região hidrofóbica, tem modificado a maneira clássica de se descrever a sua formação $0^{5,19}$. De acordo com esta nova descrição, amparada no conceito de que a constante de equilíbrio depende do meio, a energia é necessária somente para provocar uma mudança conformacional que leva à entrada (ou saída) de água no sítio catalítico e à descomplexação do éster de fosfato formado no sítio ativo da enzima. Assim, considerando-se a importância do papel da água (e de sua ausência) na formação biológica de compostos ricos em energia, mostrou-se que o íon $n$-decilfosfato em acetonitrila anidra reage facilmente com acetato de 2,4-dinitrofenila para formar o acetilfosfato correspondente, em rendimento quantitativo (Esquema 4$)^{20}$. Esta reação é fortemente inibida pela adição de pequenas quantidades de água e, em solução aquosa, os produtos são os íons acetato e 2,4-dinitrofenolato formados pela hidrólise do éster. Este modelo não-enzimático representou o primeiro sistema bioorgânico que mimetizou com sucesso a síntese de um acilfosfato e demonstrou a importância do meio não somente para aumentar a nucleofilicidade do fosfato, como também para mudar o curso da reação. Este resultado é importante porque demonstra que a solvatação deve exercer um papel principal no mecanismo de ação de enzimas responsáveis pela transferência de energia em sistemas biológicos, em consonância com as discussões recentes sobre o assunto ${ }^{19-21}$.

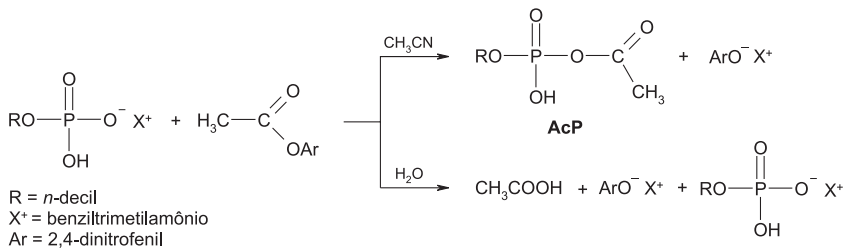

Esquema 4

\section{AGENTES NEUROTÓXICOS}

Segundo a história, a primeira utilização de armas químicas ocorreu quando a Alemanha, em 1915, durante a Primeira Guerra Mundial lançou o gás mostarda sobre as tropas aliadas na cidade de Ypres, na França ${ }^{22}$. Desde então, o desenvolvimento de agentes asfixiantes que afetam o sistema nervoso (agentes neurotóxicos) foi considerável, destacando-se os estudos sobre os agentes neurotóxicos do tipo G (Figura 2a) realizados na Alemanha, ao final da década de 30. Apesar disso, estes agentes, assim como o gás mostarda, não foram utilizados durante a Segunda Guerra Mundial.

Na década de 50, foram desenvolvidos compostos mais tóxicos e persistentes que os do tipo $\mathrm{G}$, que foram classificados como agentes neurotóxicos do tipo V (Figura 2b). A maioria são ésteres fosfóricos e, para o nosso desconforto, possuem estrutura similar àquelas dos compostos utilizados como inseticidas e pesticidas (Figura $2 \mathrm{c})^{23}$.

(a)

$\begin{array}{rrl}\mathrm{O} & \mathrm{O} & \mathrm{GB} \text { (Sarin): } \mathrm{R}=\mathrm{CH}\left(\mathrm{CH}_{3}\right)_{2} \\ \mathrm{C}_{2} \mathrm{H}_{5} \mathrm{O}-\stackrel{\mathrm{I}}{\mathrm{P}}-\mathrm{CN} & \mathrm{RO}-\stackrel{\mathrm{I}}{\mathrm{P}}-\mathrm{F} & \mathrm{GD} \text { (Soman): } \mathrm{R}=\mathrm{CH}\left(\mathrm{CH}_{3}\right)\left[\mathrm{C}\left(\mathrm{CH}_{3}\right)_{3}\right] \\ \mathrm{N}\left(\mathrm{CH}_{3}\right)_{2} & \mathrm{CH}_{3} & \text { GF }: \mathrm{R}=\mathrm{C}_{6} \mathrm{H}_{11} \text { (cicloexil) } \\ \mathbf{G A} \text { (Tabun) } & & \end{array}$

(b)

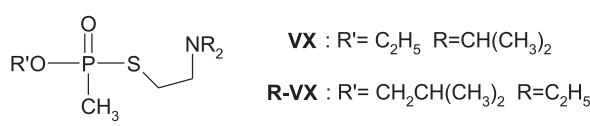

(c)<smiles>COP(=O)(OC)Oc1ccc([N+](=O)[O-])cc1</smiles>
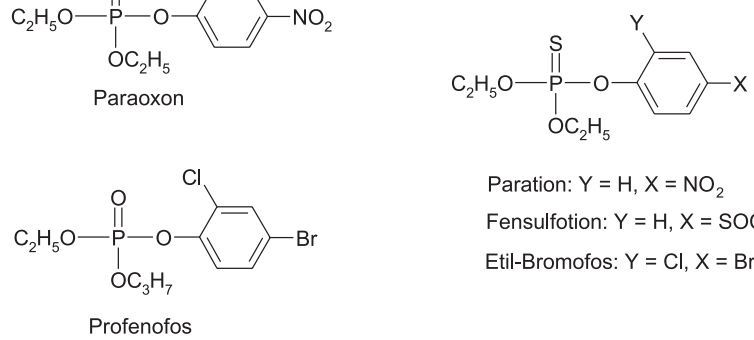

Paration: $Y=\mathrm{H}, X=\mathrm{NO}_{2}$ Fensulfotion: $Y=\mathrm{H}, X=\mathrm{SOCH}_{3}$ Etil-Bromofos: $\mathrm{Y}=\mathrm{Cl}, \mathrm{X}=\mathrm{Br}$

Figura 2. Estruturas de (a) agentes neurotóxicos do tipo $G$, (b) agentes neurotóxicos do tipo $V$ e (c) pesticidas e inseticidas

Estes compostos organofosforados inibem a ação de diversas enzimas, principalmente a acetilcolinesterase, enzima que catalisa a hidrólise da acetilcolina, um importante neurotransmissor. Assim, na ausência da acetilcolinesterase, a acetilcolina liberada acumulase, provocando um colapso no sistema nervoso central, a perda da coordenação muscular, convulsões e, finalmente, a morte ${ }^{24}$. Com apenas uma gota na pele, o agente nervoso $\mathbf{V X}$ [ $O$-etil metilfosfonotioato de $S$-2-(diisopropilamino)etila] pode matar um ser humano em poucos minutos ${ }^{25}$. Existem hoje dois agentes neurotóxicos do tipo-V estocados em larga escala: o VX, com milhares de toneladas nos Estados Unidos da América, e um isômero análogo, o R-VX [Russian-VX, $O$-isobutil metilfosfonotioato de $S$-2-(dietilamino) etila], na Rússia (Figura 2b) ${ }^{26,27}$.

A segurança e o impacto ambiental do processo de destruição destes estoques é de grande interesse e preocupação para todos. Foi neste sentido que, em 13 de janeiro de 1993, 170 países, entre os quais o Brasil, assinaram em Paris a Convenção Internacional Mundial sobre a Proibição do Desenvolvimento, Produção, Armazena- 
mento e Uso de Armas Químicas (CPAQ). Este tratado entrou em vigor no dia 29 de abril de 1997.

O texto da Convenção, além de proibir o desenvolvimento, a produção, o armazenamento e o emprego das armas químicas, estabelece um prazo de 10 anos para que os países detentores de tais armas procedam à sua destruição. Tal acordo fez crescer, a partir da década passada, o interesse na química destes compostos e em sua detoxificação (entenda-se detoxificar como retirar o caráter tóxico de um composto). Diferentes métodos de detoxificação têm sido empregados ao longo dos anos, mas nenhum com total eficiência que permita produzir resíduos sem efeitos adversos para o meio ambiente.

\section{Detoxificação química}

Em 1982, foi adotada a incineração como o método preferido para a destruição dos estoques norte-americanos. Contudo, o grande problema deste processo é que produz gases tóxicos e corrosivos, levando à necessidade de filtrá-los e purificá-los, com custo bastante elevado para um processo em larga escala. Assim, tecnologias alternativas, incluindo-se a neutralização química, estão sendo também empregadas em locais de armazenamento pré-determinados, em resposta à preocupação pública e às recomendações do Conselho Nacional de Pesquisa dos Estados Unidos.

Embora muitas reações químicas possam ser empregadas para detoxificar agentes químicos de guerra, somente algumas na prática podem ser utilizadas em uma neutralização, porque estas reações precisam ser simples e os reagentes empregados devem ser estáveis, baratos e de baixa massa molar ${ }^{28}$.

A substituição nucleofílica e a oxidação são as duas reações químicas preferidas para uma detoxificação, sob condições brandas dos agentes tóxicos. Um método bastante eficiente para detoxificar quantidades pequenas destes compostos em superfícies contaminadas ou contêineres consiste no uso de uma solução líquida contendo um excesso de reagentes para converter rapidamente, e à temperatura ambiente, os compostos em produtos significativamente menos tóxicos. Como exemplo, o sarin reage rapidamente com $\mathrm{OH}^{-}$, à temperatura ambiente em uma solução básica, para formar os produtos não tóxicos $\mathrm{NaF}$ e isopropil-metilfosfonato de sódio (Esquema 5). Entretanto, este procedimento não é eficiente para a destruição de todos os agentes neurotóxicos. O VX, por exemplo, tem solubilidade limitada em meio básico, reage lentamente com o íon hidróxido $\left(t_{1 / 2}=31 \mathrm{~min} \text { com NaOH } 0,1 \mathrm{~mol} \mathrm{~L}^{-1} \text { a } 22{ }^{\circ} \mathrm{C}\right)^{29}$ e ainda produz um subproduto estável e altamente tóxico, o ácido tióico (Esquema 6).

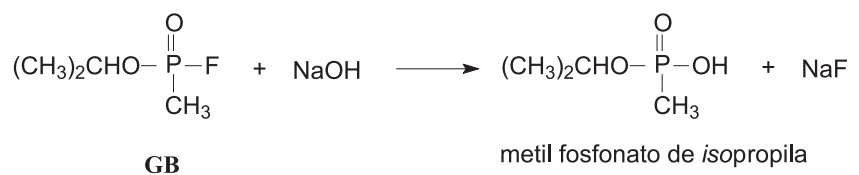

Esquema 5

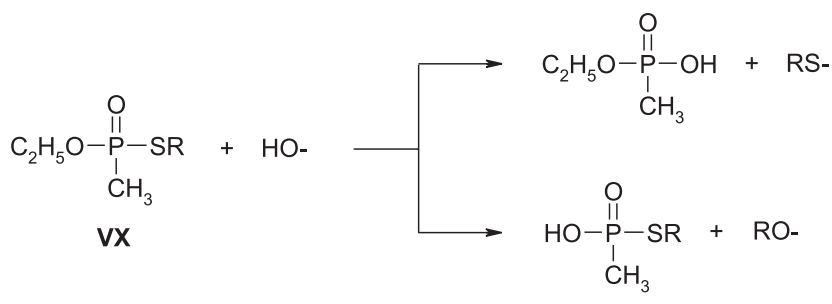

Esquema 6

Assim, a detoxificação do $\mathbf{V X}$ requer uma química diferente. Uma alternativa é o uso de peroxiácidos, que oxidam o átomo de enxofre e promovem uma rápida clivagem da ligação P-O. Por exemplo, o íon peroximonossulfato $\left(\mathrm{HSO}_{5}^{-}\right)$, utilizado numa mistura conhecida como oxone ( $2 \mathrm{KHSO}_{5} \cdot \mathrm{KHSO}_{4} \cdot \mathrm{K}_{2} \mathrm{SO}_{4}$ ), é especialmente útil, porque protege o grupo amino da oxidação por causa da protonação e também porque o $\mathbf{V X}$ protonado é bastante solúvel em água ${ }^{30}$. Contudo, o oxone tem uma massa molar alta, uma solubilidade baixa e é caro. O íon hipoclorito também destrói o VX, mas esta reação é inviável porque o oxidante é desperdiçado ao reagir com o grupo amino. Um outro aspecto importante é que, em geral, estes oxidantes têm um tempo de meia-vida curto. Uma estratégia alternativa consiste no uso de nucleófilos mais estáveis, que produzam clivagem quantitativa da ligação P-O. Dentro desta alternativa, a utilização de nucleófilos detentores do efeito $\alpha$ parece constituir uma estratégia bastante vantajosa.

O efeito $\alpha$ é definido como o aumento da reatividade de nucleófilos que têm pares de elétrons não compartilhados sobre o átomo adjacente ao centro nucleofílico, quando comparados a um nucleófilo normal (nucleófilo que não possui o efeito $\alpha$ ) de mesma basicidade. A explicação deste tipo especial de efeito tem sido um desafio contínuo para os pesquisadores, desde que este fenômeno foi trazido à luz por Edwards e Pearson ${ }^{31}$.

Dentre as espécies que exibem esta reatividade inusitada, estão incluídas a hidroxilamina, a hidrazina, o ânion hipoclorito, os ácidos hidroxâmicos, as oximas, os hidroperóxidos, o nitrito e o sulfito (Figura 3).

$$
\text { Nucleófilos tipo } \ddot{X}-Y \text { : }
$$

Rọ̈- $\ddot{\mathrm{N}} \mathrm{H}_{2}$

$\mathrm{R}_{2} \ddot{\mathrm{N}}-\ddot{\mathrm{N}} \mathrm{H}_{2}$

$: \ddot{\mathrm{C}}-\mathrm{O}^{-}$

Figura 3. Algumas espécies nucleofílicas que apresentam o efeito $\alpha$ em processos nucleofílicos

Diferentes fatores podem influenciar a reatividade nucleofílica e são importantes para o efeito $\alpha$. É provável que o átomo eletronegativo que está na posição $\alpha$ com o seu par de elétrons livres contribua diretamente para o aumento da nucleofilicidade de alguns, senão todos, destes nucleófilos. A explicação proposta mais freqüentemente para o efeito $\alpha$ é a de que os pares de elétrons sobre os átomos na posição $\alpha$ aumentam a nucleofilicidade pelo aumento da densidade eletrônica efetiva no centro de reação. Pode-se ainda argumentar que a remoção parcial dos elétrons de Y no nucleófilo X-Y (Esquema 7) por doação ao substrato $S$, no caminho que leva ao estado de transição, cria uma deficiência eletrônica sobre Y. Esta deficiência eletrônica pode ser estabilizada pela doação eletrônica de $\mathrm{X}$. $\mathrm{O}$ resultado será um aumento na densidade eletrônica efetiva no substrato e, conseqüentemente, na nucleofilicidade de $\mathrm{X}-\mathrm{Y}^{32}$.

$\mathrm{O}$ bis(2,4-dinitrofenil) fosfato (BDNPP) vem sendo utilizado como substrato para estudar a reação de hidrólise e substituição 


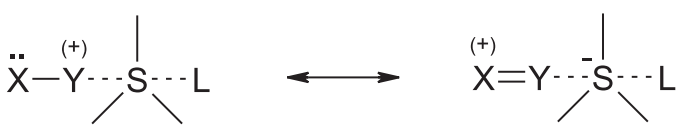

Esquema 7

nucleofílica ao centro de fósforo do BDNPP na presença de hidroxilamina (HA), $N$-metil hidroxilamina (NMHA), $N, N$-dimetil hidroxilamina (NDHA) e $O$-metil hidroxilamina (OMHA). Os resultados vêm mostrando que estas espécies nucleofílicas catalisam muito eficientemente a hidrólise de BDNPP. Além disso, verificouse que as reações de substituição nucleofílica ao centro de fósforo do BDNPP ocorrem muito provavelmente com a formação de um intermediário HA $O$-fosforilado, com ataque intramolecular ao átomo de fósforo ${ }^{33}$.

\section{REAÇÕES DE SUBSTITUIÇÃO NUCLEOFÍLICA EM ÉSTERES DE FOSFATO CATALISADAS POR ÍONS METÁLICOS}

Muitas enzimas recebem a denominação de metaloenzimas porque empregam íons metálicos como cofatores para baixar a energia de ativação da quebra de ligações químicas. O mecanismo pelo qual isso acontece depende de cada metaloenzima. Dentre esta classe de enzimas, pode-se citar as fosfatases, que usam íons metálicos para facilitar a quebra da ligação P-O. Diversos complexos metálicos que tentam modelar a estrutura e funcionalidade destas metaloenzimas têm sido extensivamente estudados nas últimas décadas e procuram elucidar o seu modo de ação $0^{34,35}$.

$\mathrm{O} t_{1 / 2}$ para a clivagem hidrolítica do DNA, em pH 7 e a $25^{\circ} \mathrm{C}$, tem sido estimado em milhões de anos. Por outro lado, o DNA e o RNA são clivados em apenas alguns segundos em condições fisiológicas quando enzimas ativadas por um, dois ou mais íons metálicos estão presentes $^{36}$. Este fato faz com que um grande número de estruturas empregadas a nível supramolecular tais como as ciclodextrinas ${ }^{37}$, os éteres-coroa ${ }^{38,39}$, os calixarenos ${ }^{40-42}$, os ácidos hidroxâmicos ${ }^{43}$ e complexos inorgânicos automontados ${ }^{44}$, assim como diversos compostos não-cíclicos, venham sendo estudados como modelos artificiais para metaloenzimas e suas funcionalidades testadas em uma diversidade de reações ${ }^{45,46}$. No entanto, a maior diferença entre as enzimas e seus modelos está na reatividade, para a qual questões como as estruturais são muito importantes.

Algumas características da catálise enzimática, tais como a complexação do substrato, o aumento de velocidade e a seletividade alta, têm levado muitos pesquisadores a desenvolverem moléculasmodelo para as propriedades estruturais e funcionais das enzimas.

\section{Catálise por íons metálicos}

A catálise por metais de transição e compostos organometálicos faz parte de um campo de investigações vasto e relativamente novo, que vem se desenvolvendo rapidamente devido à sua potencialidade para fornecer modelos de processos enzimáticos. A catálise por íons metálicos ocorre devido à sua habilidade para se coordenar ao substrato estabilizando, assim, o estado de transição. Essa estabilização é variável, dependendo de como o metal atua nas reações.

De maneira geral, um íon metálico pode promover a aceleração da velocidade de hidrólise de ésteres de fosfato através da coordenação do átomo de oxigênio do grupo fosforila ao íon metálico; pela ativação do nucleófilo, o qual é coordenado tal como um hidróxido metálico; ou ativando o grupo de saída através da coordenação deste ao metal. O íon metálico pode se coordenar a grupos hidróxido, promovendo a aceleração da velocidade de hidrólise por meio de uma catálise básica geral intramolecular, ou ainda, através da coordenação com moléculas de água, numa catálise ácida geral intramolecular $^{47}$.

A associação de um íon metálico com água ou álcool tende a baixar os seus valores de $\mathrm{p} K_{a}$. Isto é possível porque a base conjugada, hidróxido ou alcóxido, pode dissipar a carga negativa pela interação com o íon metálico, por ser melhor nucleófilo que seu ácido conjugado. De uma maneira geral, podemos dizer que, quando um íon metálico se coordena a um fosfato, é observado um aumento no caráter eletrofílico do substrato e o metal atua como um catalisador ácido geral ${ }^{47}$.

O Esquema 8 mostra como um íon metálico pode promover a reação pelo posicionamento correto do nucleófilo para o ataque sobre o átomo de fósforo. Este arranjo promove um aumento da eletrofilicidade do átomo de fósforo através da coordenação do íon metálico a um dos átomos de oxigênio do fosfato. Por outro lado, posiciona favoravelmente o hidróxido metálico para o ataque equatorial $^{48}$.

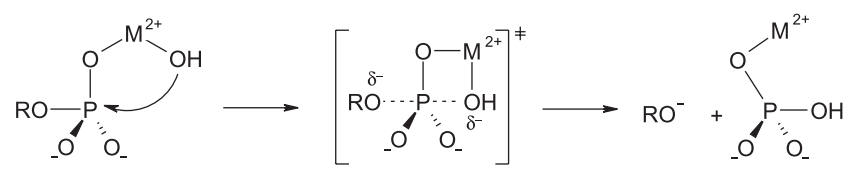

\section{Esquema 8}

Fife e Pujari ${ }^{49}$ estudaram a influência dos íons metálicos $\mathrm{Cu}^{2+}$, $\mathrm{Ni}^{2+}, \mathrm{Co}^{2+} \mathrm{e} \mathrm{Zn}{ }^{2+}$ na hidrólise do monoéster 2-(1,10-fenantrolil)fosfato (1). O íon metálico tem a função de aumentar a estabilidade do grupo de saída. O valor da constante de velocidade para a hidrólise do complexo do diânion de $\mathbf{1} \mathrm{com} \mathrm{Cu}^{2+}$ foi $10^{8}$ vezes maior que para o diânion fenilfosfato.

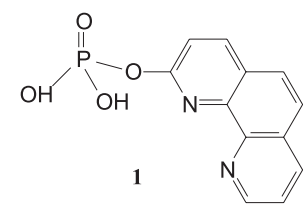

Bruice e colaboradores ${ }^{50}$ observaram a importância da questão estrutural dos substratos fosfatados em processos hidrolíticos. Foi verificado que os íons metálicos $\mathrm{Ni}^{2+}, \mathrm{Co}^{2+} \mathrm{e} \mathrm{Zn}^{2+}$ catalisam a reação de hidrólise do bis(8-hidroxiquinolina)fosfato (2), mas não têm efeito sobre a velocidade de hidrólise do bis(6-hidroxiquinolina)fosfato (3).
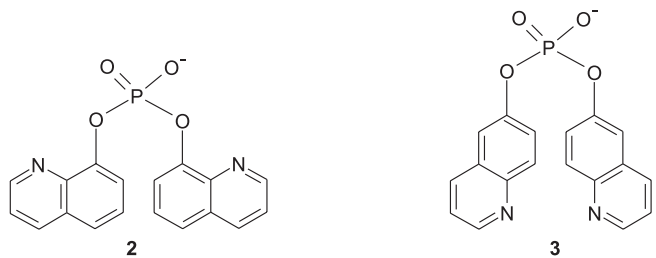

O mecanismo mais provável para a reação catalisada pelo íon metálico pode ser representado segundo o Esquema 9. A função do íon metálico aqui é a de gerar um grupo de saída bom pela sua préassociação com 2.

Os ésteres 4-nitrofenilfosfato (4) e bis(4-nitrofenil) fosfato (5), quando complexados a íons $\mathrm{Co}^{3+}$ coordenados a poliaminas, mostram um aumento nas velocidades de hidrólise de $10^{10}$ vezes em $\mathrm{pH}$ 7, comparativamente com a hidrólise espontânea dos respectivos ésteres não complexados ${ }^{51}$. Estes grandes aumentos nas velocidades 

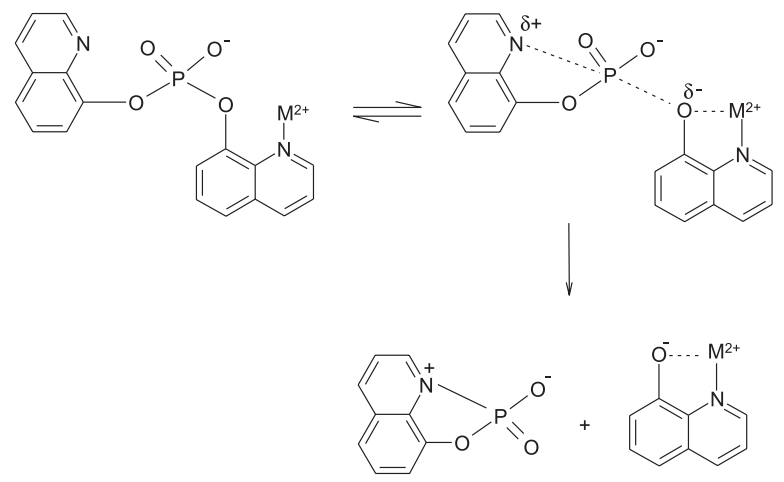

Esquema 9

devem-se muito provavelmente às estruturas 6 e 7, nas quais o éster encontra-se ligado ao íon $\mathrm{Co}^{3+}$.<smiles>O=[N+]([O-])c1ccc(OP(=O)(O)O)cc1</smiles><smiles>O=[N+]([O-])c1ccc(OP(=O)(O)Oc2ccc([N+](=O)[O-])cc2)cc1</smiles>
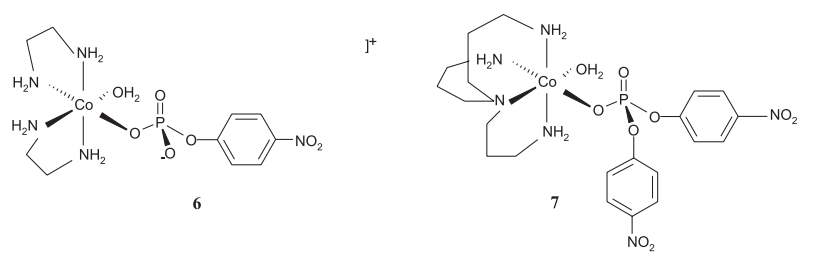

As fosfoesterases catalisam a hidrólise de ésteres de fosfato e dentre elas merecem citação as fosfatases ácidas púrpuras (PAP's), que catalisam a hidrólise de ésteres de fosfato em condições ácidas (pH ótimo entre 4,9 e 6,0) e contêm um centro dinuclear de Fe-M, sendo $\mathrm{M}$ igual a $\mathrm{Fe}, \mathrm{Mn}$ ou $\mathrm{Zn}^{52}$. As PAP's são encontradas em uma grande variedade de plantas e animais, sendo que as mais estudadas têm sido as encontradas no baço bovino, com função biológica ainda não muito bem esclarecida. Diversos pesquisadores têm trabalhado em propostas para o sítio ativo das PAP's, tentando aproximar os complexos-modelo com a enzima natural ${ }^{53-58}$. Os centros metálicos dinucleares em grande número de fosfoesterases ligam-se a fosfatos e promovem sua hidrólise ${ }^{59,60}$. A ativação do ácido de Lewis obtida pela coordenação dos átomos de oxigênio do fosfodiéster com uma variedade de complexos metálicos dinucleares pode aumentar a velocidade da reação de hidrólise. Sob esta ótica, estudou-se o efeito catalítico do complexo (8a) sobre a reação de hidrólise do BDNPP (8b). Este complexo foi sintetizado inicialmente por Erthal ${ }^{61} \mathrm{e}$ apresenta em sua estrutura dois íons $\mathrm{Fe}^{3+}$. Os resultados mostraram um efeito catalítico máximo, entre $\mathrm{pH}$ 5,0 e 5,5, de aproximadamente 200 vezes em comparação com a hidrólise espontânea do éster ${ }^{62}$.

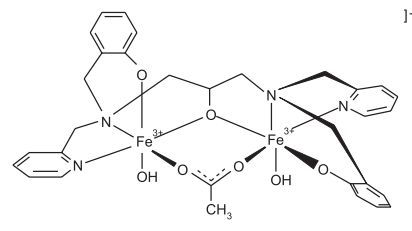

$8 \mathbf{a}$

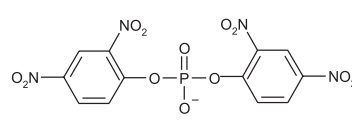

$8 b$
A baixa velocidade de troca dos ligantes em complexos com $\mathrm{Co}^{3+}$ faz com que sejam ideais, tanto para quantificar a ativação do ácido de Lewis como para o estudo em detalhes do mecanismo da reação. O complexo 9, que apresenta um diéster de fosfato coordenado a um

centro dinuclear de $\mathrm{Co}^{3+}$, foi empregado no estudo da labilidade isotópica de ${ }^{18} \mathrm{O}$ para mostrar que a ponte óxido atua como um nucleófilo bastante eficiente na hidrólise de fosfato ${ }^{63}$. A ativação do ácido de Lewis, em combinação com a ativação da ponte hidróxido, provoca um aumento de, aproximadamente, 11 ordens de magnitude na hidrólise do diéster de fosfato no complexo $\mathbf{9}^{64}$.

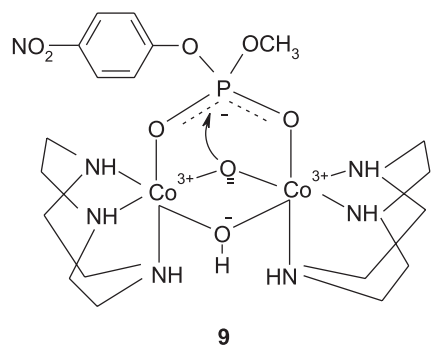

Os íons hidróxido coordenados a dois íons metálicos em aminopeptidases e fosfatases podem funcionar como nucleófilos ${ }^{59}$. No entanto, é bastante difícil recolher evidências sobre os mecanismos pelos quais as enzimas catalisam as reações de hidrólise de ésteres de fosfato.

\section{Catálise por lantanídeos}

Nos últimos anos, os lantanídeos têm despertado a atenção dos pesquisadores como catalisadores em reações de hidrólise de ésteres fosfóricos. A forma pela qual estes processos ocorrem e quais são as espécies ativas são algumas dentre as muitas questões que precisam ainda ser investigadas. Há várias possibilidades sendo discutidas na literatura ${ }^{65,66}$ e é sobre elas que a questão será aqui abordada, tentando-se mostrar os pontos de vista dominantes e as bases experimentais para as discussões.

A carga total do íon metálico e a sua habilidade para polarizar as ligações P-O são fatores importantes no estudo dos mecanismos de reações promovidas por metais. Os lantanídeos $\left(\mathrm{Ln}^{3+}\right)$ apresentam vantagens sobre os metais de transição na eficiência catalítica devidas, em grande parte, ao efeito da carga, ao elevado número de coordenação em solução (entre 8 e 9) e à sua restrição geométrica relativamente livre se comparada aos metais de transição $0^{43,65}$.

Os ésteres de fosfato tais como o composto $\mathbf{5}$, normalmente resistentes a agentes nucleofílicos, são facilmente hidrolisados na presença de lantanídeos. Isto ocorre pela capacidade que estes metais têm para disponibilizar simultaneamente sítios receptores eletrofílicos

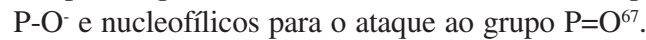

$\mathrm{O} t_{12}$ para a hidrólise espontânea dos nucleotídeos UpU (10) e ApA (11) é estimado em 130 anos. Na presença do lantanídeo $\mathrm{Tm}^{3+}$, o $t_{1 / 2}$ passa a ser de apenas $10 \mathrm{~min} \mathrm{em} \mathrm{pH} 8$ e a $30{ }^{\circ} \mathrm{C}$, tendo um incremento de velocidade na ordem de $10^{7}$. No entanto, a catálise não é observada se o lantanídeo for substituído por metais de transição ${ }^{68}$.

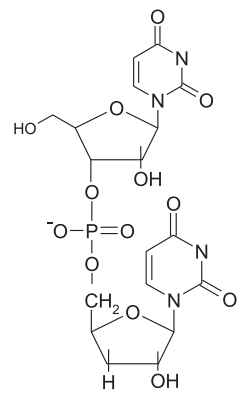

10

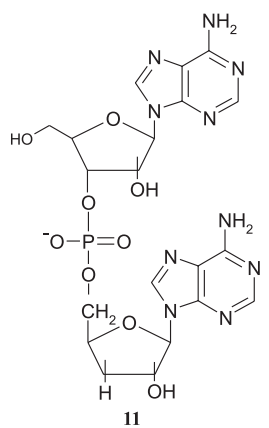

11

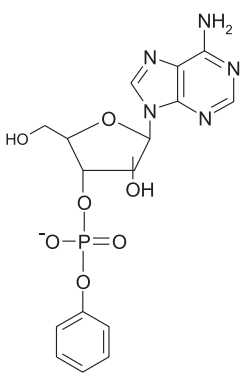

12 
Os resultados experimentais de Chin e colaboradores ${ }^{69}$ para a hidrólise do ApA com $\mathrm{La}^{3+}$, em valores de $\mathrm{pH}$ variando entre 8,4 e 9,9 a $25^{\circ} \mathrm{C}$, são consistentes com um complexo em que estão envolvidos dois íons metálicos associados a cinco moléculas de água desprotonadas, formando um dímero do tipo $\mathrm{La}_{2}(\mathrm{OH})_{5}{ }^{+}$, que é aproximadamente $10^{4}$ vezes mais reativo do que os complexos mononucleares correlacionados ${ }^{68}$. Os autores sugerem dois mecanismos possíveis. No primeiro caso, um dos íons hidróxido ligar-se-ia ao metal e faria o papel de um catalisador básico geral intramolecular (Esquema 10a). Na outra possibilidade, o 2'-alcóxido deslocaria um hidróxido ligado e agiria como nucleófilo (Esquema 10b).
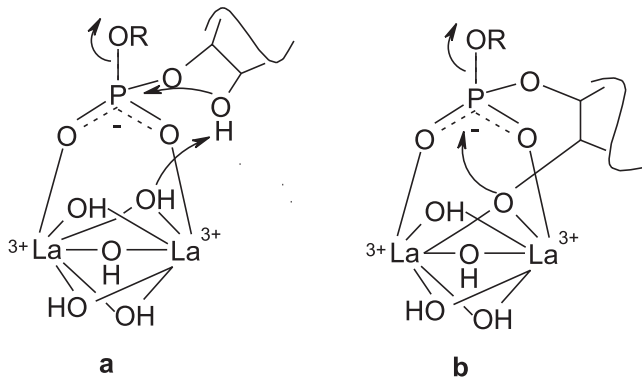

Esquema 10

Os resultados de Chin e colaboradores ${ }^{69}$ opõem-se aos resultados obtidos por Matsumura e Komiyama ${ }^{70}$ quanto à espécie ativa formada entre o metal e íons hidróxido. Segundo os últimos autores, a espécie ativa teria uma estrutura tetracatiônica do tipo $\left[\mathrm{Ln}_{2}(\mathrm{OH})_{2}\right]^{4+71}$. Embora tenha se mostrado bastante complicada a definição precisa das espécies que se formam em solução, todos os experimentos convergem para a existência de espécies altamente agregadas. Esses oligômeros podem ser representados como $\left[\mathrm{Ln}_{\mathrm{m}}(\mathrm{OH})_{\mathrm{n}}\right]^{3 \mathrm{~m}-\mathrm{n}}$, nos quais a estrutura depende em grande parte dos dados de solvólise para cada metal.

A sugestão de que espécies bimetálicas atuam ativamente na clivagem de ribonucleotídeos é reforçada por outros pesquisadores $^{43,72}$. Além disso, a cooperatividade bimetálica observada nestes trabalhos lembra os mecanismos observados por algumas metaloenzimas naturais ${ }^{59,60}$. A substituição do grupo de saída 5'alcóxido da ApA por um grupamento fenila $\operatorname{Ap} \phi$ (12) faz com que a hidrólise tenha um incremento de velocidade na ordem de $10^{5}$. Em contraste com a ApA, que tem aumentos de velocidade de hidrólise extremamente grandes na presença de lantanídeos, como já foi anotado anteriormente, a velocidade da reação da Ap $\phi$ na presença de $\mathrm{Tm}^{3+}$ é somente três vezes maior do que para a reação sem metal. Este resultado sugere, aparentemente, que a etapa determinante na velocidade da reação é diferente para ambos os compostos ApA e Apф e evidencia, também, a importante participação do grupo de saída na velocidade das reações de substituição nucleofílica dos ésteres de fosfato ${ }^{70}$

Muitos trabalhos levam a evidências de que a hidrólise de ésteres de fosfato promovida por metais ocorre via mecanismo concertado, através de um complexo formado entre um cátion metálico e um nucleófilo $\left(\mathrm{OH}^{-} \text {ou } \mathrm{RO}^{-}\right)^{34,50,73}$.

Para gerar complexos lantanídeo/hidroxo ativos, um meio básico é requerido. No entanto, a baixa estabilidade dos hidróxidos de lantanídeos nesse meio torna necessário o uso de ligantes apropriados que estabilizem a espécie reativa. Este é, sem dúvida, um dos fatores mais importantes no desenvolvimento de catalisadores ativos. Aminas, aminoésteres e polióis, quando usados como ligantes complexando o íon $\mathrm{Eu}^{3+}$ na reação de hidrólise do composto 5, não afetam significativamente a velocidade da reação ${ }^{74,75}$. Este resultado evidencia que ligantes neutros, como os amino-álcoois, podem funcionar como bons estabilizantes dos complexos, sem diminuir a eficiência catalítica dos mesmos em valores de $\mathrm{pH}$ elevados. Devido a este fato, amino-álcoois simples como os derivados de tris(hidroximetil)-aminometano (13; tris) têm recentemente despertado muito a atenção e sido empregados com sucesso. O tris mostra-se bastante eficiente na estabilização de complexos de $\mathrm{Zr}^{4+}$ altamente ácidos ${ }^{76}$ enquanto o bis-tris (14) e o bis-tris-propano (15) formam complexos hidroliticamente ativos com $\mathrm{La}^{3+61,66,77}$.<smiles>NC(CO)(CO)CO</smiles><smiles>OCCN(CCO)C(CO)(CO)CO</smiles><smiles>OCC(CO)(CO)NCCCNC(CO)(CO)CO</smiles>

Efeito de $\mathbf{L n}^{3+}$ com espécies nucleofílicas nas reações de substituição envolvendo ésteres de fosfato

Butcher e Westheimer ${ }^{78}$, já nas primeiras décadas do século XX, discutiam o alto efeito catalítico dos lantanídeos associados com íons hidróxido na substituição nucleofílica em ésteres de fosfato. Atualmente, o interesse tem se voltado para estes metais pois, além de atuarem como íons livres, podem se combinar entre si em água, formando espécies oligoméricas. Com espécies nucleofílicas, como o peróxido de hidrogênio, podem formar nucleófilos metálicos mais eficientes, aumentando ainda mais seu poder catalítico ${ }^{50,79,80}$. Vários trabalhos na literatura relatam efeitos sinérgicos de velocidade de hidrólise de ésteres de fosfato, quando lantanídeos são associados com espécies nucleofílicas ${ }^{81,82}$.

A clivagem do éster fosfórico 5 na presença de $\mathrm{La}^{3+} \mathrm{em} \mathrm{pH} \mathrm{7,0} \mathrm{a}$ $25{ }^{\circ} \mathrm{C}$ é da ordem de $10^{4}$ vezes mais rápida em comparação com a hidrólise na ausência do lantanídeo. No entanto, a mesma reação apresenta um incremento na velocidade de hidrólise de aproximadamente $10^{8}$ vezes, quando o peróxido de hidrogênio é adicionado ao meio reacional ${ }^{81}$. O grande aumento observado na velocidade da reação está associado a interações cooperativas do íon metálico com o peróxido de hidrogênio, formando um catalisador (Esquema $10 \mathrm{ou}$ 11) que apresenta uma coroa ativa, a qual consiste em dois íons $\mathrm{La}^{3+}$ ligados a dois peróxidos reativos (Esquema 11).

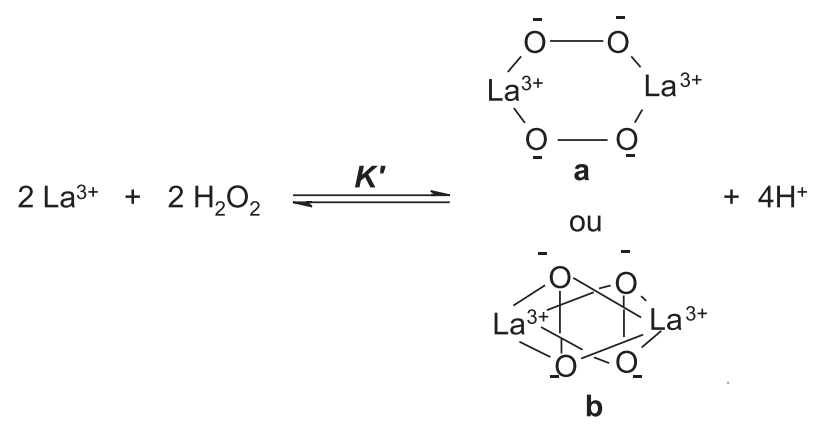

Esquema 11

A função mecanística do peróxido de hidrogênio pode estar relacionada à formação de complexos dinucleares (Esquema 12), possibilitando assim a ligação do fosfato como ponte entre os centros metálicos (Esquema 12a). Adicionalmente, o peróxido pode atuar como uma base geral intramolecular (Esquema 12b). Finalmente, pode atuar como um catalisador nucleofílico intramolecular levando à formação de um peroxifosfato (Esquema 12c). 

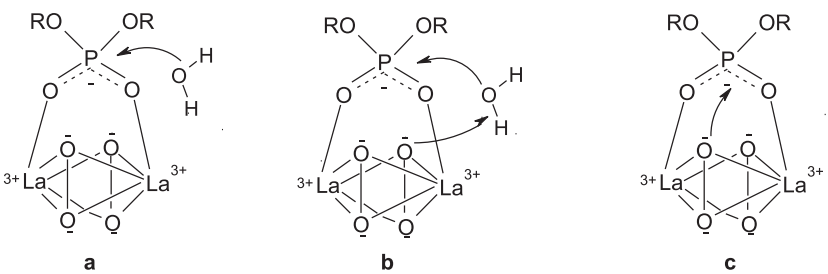

Esquema 12

Nas condições descritas acima para a hidrólise do composto 5 na presença de $\mathrm{La}^{3+}$ e de peróxido, a constante de velocidade mostra-se de segunda ordem em relação ao lantânio e, também, em relação ao peróxido e dados de titulação potenciométrica são consistentes com o mecanismo proposto no Esquema $12^{80}$. Estudos de efeito isotópico com $\mathrm{H}_{2}{ }^{18} \mathrm{O}_{2}$ para esta reação evidenciam a presença de ${ }^{18} \mathrm{O}$ no produto da reação $\left(\mathrm{PO}_{4}^{3-}\right)$, sugerindo que o peróxido atua como catalisador nucleofílico e forma a espécie peroxifosfato que é, então, reduzida pelo peróxido ao fosfato correspondente ${ }^{80}$.

A observação de que a associação dos lantanídeos com grupos nucleofílicos leva a efeitos sinérgicos altamente pronunciados sobre as velocidades de reações de substituição nucleofílica em ésteres de fosfato está fazendo com que, nos últimos anos, outros ligantes ${ }^{75,79,83,84}$ sejam estudados, com o intuito de se compreender melhor o mecanismo pelo qual estes processos ocorrem. Assim, por exemplo, um efeito catalítico extraordinário foi observado para a hidrólise do éster 8b na presença de um complexo de $\mathrm{Er}^{3+}$ com o ligante 15. Em pH 8,5 , foi observado um efeito catalítico de $10^{5}$ vezes em comparação com a hidrólise espontânea do éster de fosfato ${ }^{33,85}$.

\section{CONCLUSÕES}

A importância da química do átomo de fósforo por si só justificaria o estudo de seus compostos. O fato de que os compostos fosfatados são utilizados como fonte de energia nos processos biológicos dão aos ésteres derivados do ácido fosfórico um papel fundamental para o desempenho de muitas funções vitais nos organismos vivos. De acordo com Westheimer, "todas as reações que envolvam a formação ou a quebra de ligações de ésteres fosfóricos são vitais para o entendimento dos sistemas vivos" ${ }^{\prime 17}$. Com isso, a busca do entendimento do papel biológico destes compostos tem contado com a contribuição de muitos pesquisadores, nas últimas décadas. Assim, destacou-se aqui a importância biológica dos ésteres de fosfato, a sua reatividade e os mecanismos propostos para suas reações de substituição nucleofílica. Fica claro pelo que foi aqui apresentado que, embora tais mecanismos venham sendo amplamente discutidos ao longo das últimas cinco décadas, ainda permanecem muitas incertezas.

Outro aspecto de grande importância, que merece ser melhor estudado, refere-se ao estudo de estratégias para a degradação de fosfatos de alta toxicidade, baseando-se em reações de compostosmodelo com $\alpha$-nucleófilos. Estes estudos devem ainda fornecer importantes subsídios para a compreensão da origem mecanística do efeito $\alpha$.

Tendo-se em vista a relevância do uso de lantanídeos como catalisadores das reações de substituição nucleofílica envolvendo ésteres de fosfato, as investigações mecanísticas destes processos catalisados representam um campo que vem tendo um crescimento vertiginoso, merecendo a atenção de vários pesquisadores. É importante ressaltar que a complexidade destes sistemas modelos apresenta características muito similares às de muitas enzimas que exibem o fenômeno da cooperatividade ${ }^{59,60}$, o que os torna, por este motivo, um objeto de estudo sempre atual.

\section{AGRADECIMENTOS}

Os autores agradecem à Capes, ao CNPq e ao PRONEX pelo apoio financeiro.

\section{REFERÊNCIAS}

1. Corbridge, D. E. C. Em Phosphorus: An outline of its Chemistry, Biochemistry and Technology; Elsevier Scientific Publishing Company: Amsterdam, 1978.

2. Saenger, W.; Principles of Nucleic Acid Structure, Springer: New York, 1984.

3. Dugas, H.; Bioorganic Chemistry: A Chemical Approach to Enzyme Action, $3^{\text {rd }}$ ed., VCH: New York, 1996.

4. Westheimer, F. H.; Science 1987, 235, 1173.

5. Machado, V. G.; Nome, F.; Quim. Nova 1999, 22, 351.

6. Yang, Y.-C.; Baker, J. A.; Ward, J. R.; Chem. Rev. 1992, 92, 1729.

7. Kirby, A. J.; Younas, M.; J. Chem. Soc. B 1970, 6, 510.

8. Thatcher, G. R. J.; Kluger, R.; Adv. Phys. Org. Chem. 1989, 25, 99.

9. Bruice, T. C.; Benkovic, S. J. Em Bioorganic Mechanisms; Benjamin, W. A., ed.; New York, 1966.

10. Cox, J. R.; Ramsay, O. B.; Chem. Rev. 1964, 64, 317.

11. Lum, R. C.; Grabowski, J. J.; J. Am. Chem. Soc. 1992, 114, 8619.

12. Mitchell, M. L.; Tian, F.; Lee, L. V.; Wong, C. H.; Angew. Chem., Int. Ed. 2002, 41, 3041 .

13. Florián, J.; Warshel, A.; J. Phys. Chem. B 1998, 102, 719.

14. Gillespie, P.; Ramirez, F.; Ugi, I.; Angew. Chem., Int. Ed. 1973, 12, 91.

15. Buchwald, S. L.; Pliura, D. H.; Knowles, J. R.; J. Am. Chem. Soc. 1984, $106,4916$.

16. Freeman, S.; Friedman, J. M.; Knowles, J. R.; J. Am. Chem. Soc. 1987, $109,3166$.

17. Westheimer, F. H.; Acc. Chem. Res. 1968, 1, 70.

18. Aqvist, J.; Kolmodin, K.; Florián, J.; Warshel, A.; Chem. Biol. 1999, 6, R71.

19. de Meis, L.; Biochim. Biophys. Acta 1989, 973, 333; de Meis, L.; Arch. Biochem. Biophys. 1993, 306, 287.

20. Machado, V. G.; Nome, F.; Chem. Commun. 1997, 1917; Machado, V. G.; Bunton, C. A.; Zucco, C.; Nome, F.; J. Chem. Soc., Perkin Trans. 22000, 169.

21. Westheimer, F. H.; Chem. Rev. 1981, 81, 313.

22. McWilliams, J. L.; Steel, R. J.; Gas! The Battle for Ypres, 1915, Vanwel Publishing Limited: Deyell Co.:Canada, 1985.

23. Yang, Y.-C.; Szafraniec, L. L.; Beaudry, W. T.; J. Org. Chem. 1993, 58, 6964.

24. Cremlyn, R. J. Em Agrochemicals: Preparation and Mode of Action; John Wiley \& Sons Ltd.: West Sussex, 1991, p. 105.

25. Benschop, H. P.; Dejong, L. P. A.; Acc. Chem. Res. 1988, 21, 368.

26. Voronov, V.; Fedorov, L.; Moscom Khim. Zh. 1993, 7, 66.

27. Beletskaya, I. P.; Novikov, S. S.; Vestn. Ross. Akad. Nauk. 1995, 65, 99.

28. Yang, Y.-C.; Chem. Ind. 1995, 334.

29. Epstein, J.; Callahan, J. J.; Bauer, V. E.; Phosphorus 1974, 4, 157.

30. Yang, Y.-C.; Szafraniec, L. L.; Beaudry, W. T.; Rohrbaugh, D. K.; J. Am. Chem. Soc. 1990, 112, 6621.

31. Edwards, J. O.; Pearson, R. G.; J. Am. Chem. Soc. 1962, 84, 16.

32. Gerstein, J.; Jencks, W. P.; J. Am. Chem. Soc. 1964, 86, 4655.

33. Longhinotti, E.; Domingos, J. B.; Nome, F.; Resumos da Sixth Latin American Conference on Physical Organic Chemistry, Isla de Margarita, Venezuela, 2001.

34. Krämer, R.; Coord. Chem. Rev. 1999, 182, 243.

35. Averill, B. A.; Merkx, M.; J. Am. Chem. Soc. 1999, 121, 6683.

36. Bruice, T. C.; Tsubouchi, A.; J. Am. Chem. Soc. 1995, 117, 7399.

37. Breslow, R.; Acc. Chem. Res. 1995, 28, 146.

38. Lehn, J.-M.; Supramolecular Chemistry, VCH: Heidelberg, 1995.

39. Gokel, G.W.; Crown Ethers and Cryptands, Royal Society of Chemistry: Cambridge, 1994.

40. Shinkai, S.; Pure Appl. Chem. 1986, 58, 1523.

41. Lazzarotto, M.; Nachtigall, F. F.; Nome, F.; Quim. Nova 1995, 18, 444.

42. Gutsche, D. C.; Calixarenes, Royal Society of Chemistry: Cambridge, 1992.

43. Nakamura, Y.; Hashimoto, S.; J. Chem. Soc., Perkin Trans. 1 1996, 2623.

44. Machado, V. G.; Baxter, P. N. W.; Lehn, J.-M.; J. Braz. Chem. Soc. 2001 $12,431$.

45. Suh, J.; Kim, N.; J. Org. Chem. 1994, 59, 1561

46. Chin, J.; Acc. Chem. Res. 1991, 24, 145.

47. Chin, J.; Williams, N. H.; Kakasaki, B.; Wall, M.; Acc. Chem. Res. 1999, 32,485 . 
48. Gani, D.; Wilkie, J.; Chem. Soc. Rev. 1995, 24, 55.

49. Fife, T. H.; Pujari, M. P.; J. Am. Chem. Soc. 1988, 110, 7790.

50. Bruice, T. C.; Blaskó, A.; Acc. Chem. Res. 1999, 32, 475.

51. Browne, A. K.; Bruice, T. C.; J. Am. Chem. Soc. 1992, 114, 4951.

52. Klabunde, T.; Strater, N.; Fröhlich, R.; Witzel, H.; Krebs, B.; J. Mol. Biol. 1996, 259, 737

53. de Brito, M. A.; Neves, A.; Zilli, L. R.; Quim. Nova 1997, 20, 154.

54. Krebs, B.; Schepers, K; Bremer, B.; Henkel, G.; Althaus, E.; Mullerwarmuth, W.; Griesar, K.; Haase, W.; Inorg. Chem. 1994, 33, 1907.

55. Neves, A.; Erthal, S. M. D.; Drago, V.; Griesar, K.; Haase,W.; Inorg. Chim. Acta 1992, 197, 121.

56. Neves, A.; de Brito, M. A.; Vencato, I.; Drago, V.; Griesar, K.; Haase, W.; Inorg. Chem. 1996, 35, 2360.

57. Vincent, J. B.; Crowder, M. W.; Averill, B. A.; Biochemistry 1991, 30, 3025

58. Neves, A.; Terenzi, H.; Horner, R.; Horn, A.; Szpoganicz, B.; Sugai, J.; Inorg. Chem. Commun. 2001, 4, 388.

59. Wilcox, D. E.; Chem. Rev. 1996, 96, 2435.

60. Strater, N.; Lipscomb, W. N.; Klabunde, T.; Krebs, B.; Angew. Chem., Int. Ed. 1996, 35, 2024

61. Erthal, S. M. D.; Tese de Doutorado, Universidade Federal de Santa Catarina, Brasil, 1994.

62. Longhinotti, E.; Yunes, S. F.; Szpoganicz, B.; Nome, F.; Resumos da $5^{\text {th }}$ Latinamerican Conference on Physical Organic Chemistry, Viña del Mar, Chile, 1999.

63. Williams, N. H.; Cheung, W.; Chin, J.; J. Am. Chem. Soc. 1998, 120, 8079

64. Wahnon, D.; Lebuis, A. M.; Chin, J.; Angew. Chem., Int. Ed. 1995, 34, 2412 .

65. Morrow, J. R.; Buttrey, L. A.; Berbach, K. A.; Inorg. Chem. 1992, 31, 16.

66. Yatsimirsky, A. K.; Gomes-Tagle, P.; J. Chem. Soc., Dalton Trans. 1998, 2957; Yatsimirsky, A. K.; Gomes-Tagle, P.; Inorg. Chem. 2001, 40, 3786.
67. Moss, R. A.; Park, B. D.; Scrimin, P.; Ghirlanda, G.; J. Chem. Soc., Chem. Commun. 1995, 1627.

68. Komiyama, M.; Matsumura, K.; Matsumoto, Y.; J. Chem. Soc., Chem. Commun. 1992, 640.

69. Chin, J.; Takasaki, B. K.; Hurst, P.; J. Am. Chem. Soc. 1996, 118, 9982.

70. Komiyama, M.; Matsumura, K.; J. Biochem. 1997, 122, 387.

71. Singhal, A.; Toth, L. M.; Lin, J. S.; Affholter, K.; J. Am. Chem. Soc. 1996, $118,11529$.

72. Schneider, H. J.; Hettich, R.; Roigk, A.; Inorg. Chem. 1998, 37, 751.

73. Molenveld, P.; Engebersen, J. F. J.; Reinhoudt, D. N.; Chem. Soc. Rev. 2000, 29,75 .

74. Schneider, H. J.; Rammo, R.; Hettich, R.; Angew. Chem., Int. Ed. 1993, $32,1716$.

75. Schneider, H. J.; Ragunathan, K. G.; Angew. Chem., Int. Ed. 1996, 35, 1219.

76. Krämer, R.; Ott, R.; Angew. Chem., Int. Ed. 1998, 37, 1957.

77. Oh, S. J.; Choi, Y. S.; Hwangbo, S.; Bae, S. C.; Ku, J. K.; Park, J. W.; Chem. Commun. 1998, 2189.

78. Butcher, W. W.; Westheimer, F. H.; J. Am. Chem. Soc. 1955, 77, 2420

79. Chin, J.; Takasaki, B. K.; J. Am. Chem. Soc. 1994, 116, 1121.

80. Chin, J.; Takasaki, B. K.; J. Am. Chem. Soc. 1995, 117, 8582.

81. Chin, J.; Takasaki, B. K.; J. Am. Chem. Soc. 1993, 115, 9337.

82. Komiyama, M.; Kamitani, J.; Sumaoka, J.; Asanuma, H.; J. Chem. Soc., Perkin Trans. 2 1998, 523

83. Morrow, J.; Aures, K.; Epstein, D.; J. Chem. Soc., Chem. Commun. 1995, 2431.

84. Breslow, R.; Zhang, B.; J. Am. Chem. Soc. 1994, 116, 7893.

85. Longhinotti, E.; Mioto, P. C.; Zinner, L. B.; Nome, F.; Resumos da $24^{a}$ Reunião Anual da Sociedade Brasileira de Química, Poços de Caldas, Brasil, 2001. 